\title{
Participation in bowel emptying children and adolescents with neurogenic bladder and bowel Marika Persson* and Inger Odeholm
}

\author{
Address: The Regional Rehabilitation Centre for Children and Adolescents, The Queen Silvia Children's Hospital, Box 210 62, SE-41804 \\ Gothenburg, Sweden \\ Email: Marika Persson* - marika.u.persson@vgregion.se \\ * Corresponding author
}

from 52nd Annual Meeting of the Society for Research into Hydrocephalus and Spina Bifida

Providence, RI, USA. II-I 4 June 2008

Published: 3 February 2009

Cerebrospinal Fluid Research 2009, 6(Suppl I):S50 doi:10.I I86/I743-8454-6-SI-S50

This abstract is available from: http://www.cerebrospinalfluidresearch.com/content/6/SI/S50

(c) 2009 Persson and Odeholm; licensee BioMed Central Ltd.

\section{Background}

All children and adolescents with myelomeningocele born in the western of Sweden are cared for The Queen Silvia Children's Hospital, Gothenburg. The Regional Rehabilitation Centre for Children and Adolescents take care of children and adolescents (of $0-18$ of age) with Neutrogena bladder and bowels. There is a team including registered nurses/urotherapists, paediatric urologist, paediatric neurologist and occupational therapists. Urineand faeces incontinence is a common problem, if not treated or supported, which can be psychosocial problem, with isolation and difficulties in contact with other people.

The children/adolescents visit us at least yearly, for urological controls, investigations and follow-ups of treatment by the team, but also to find out how to empty their bowels. The target is obtaining bladder- and bowel continence - and to be autonomy to the greatest extent possible.

We know that these patients usually have cognitive problems that can give consequences in their daily situation and for their quality of life.

Of all cognitive difficulties it is impairment in executive functions as initiative capability, planning of action, focus on realisation and awareness of time, which are vital importance to create independence, purpose fullness and self-care.

\section{Materials and methods}

156 children/adolescents visit the division yearly.

Work structural for participation in bowel emptying.

\section{Results}

A handbook as support meant for children/adolescents, parents and other caregivers.

\section{Conclusion}

To early arouse awareness and with understandable individual structure facilitate the active participation towards independence. 